\title{
A Demographical Assessment of Different Insulin Regimens in Non-insulin Dependent Diabetics
}

\author{
Sajjad Ali ${ }^{1^{*}}$, Syed Atif Raza ${ }^{2}$, Humayun Riaz ${ }^{1}$, Mobasher Ahmad Butt ${ }^{2}$, \\ Hamid Saeed ${ }^{2}$, Zikria Saleem ${ }^{2}$, Tanveer Ahmed Khan ${ }^{1}$, \\ and Muhammad Ishfaq Ahmad ${ }^{1}$ \\ ${ }^{1}$ Rashid Latif College of Pharmacy, Lahore, Pakistan. \\ ${ }^{2}$ University College of Pharmacy, University of the Punjab, Lahore, Pakistan.
}

\begin{abstract}
Authors' contributions
This work was carried out in collaboration between all authors. Author SA designed the study, performed the statistical analysis, wrote the protocol and the first draft of the manuscript. Author MAB was supervisor of the study. Authors HS and ZS were co-supervisors. Authors SAR, HR, TAK and MIA managed analyses of the study. Authors SA and TAK managed the literature searches. All authors read and approved the final manuscript.
Article Information
DOI: 10.9734/BJPR/2017/33437 Editor(s): (1) Othman Ghribi, Department of Pharmacology, Physiology \& Therapeutics, University of North Dakota, USA.
Reviewers:
(1) Elvira Bormusov, Technion Institute of Technology, Israel. (2) Bidita Khandelwal, Sikkim Manipal Institute of Medical Sciences Sikkim, India. (3) Mario Bernardo-Filho, Universidade do Estado do Rio de Janeiro, Brazil. (4) Mustapha Diaf, Djillali LIABES University, Algeria. Complete Peer review History: http://www.sciencedomain.org/review-history/19311

Original Research Article

Received $15^{\text {th }}$ April 2017

Accepted $22^{\text {th }}$ May 2017

Published $2^{\text {nd }}$ June 2017

\section{ABSTRACT}

Aims: The aim of present study was to evaluate the clinical efficacy of different insulin regimens in non-insulin dependent diabetic patients with respect to their age and gender.

Methodology: A prospective cross-sectional study was conducted for comparing different insulin regimens in type II diabetic patients for better glycemic control with respect to age and gender. A total of 234 consenting, known type II diabetic patients, on any insulin regimens, with at least all relevant medical records of preceding three months participated in the study. Patients were segregated into six treatment arms depending upon type of insulin prescribed i.e., insulin pre-mix 70/30, insulin split mix ( $N \& R$ ), long acting insulin analogue, ultra-short acting insulin analogue, insulin pre-mix 70/30 analogue and insulin pre-mix 50/50 analogue, respectively. Moreover, patients from each group were evaluated regarding diabetes knowledge and medication adherence using Michigan Diabetes Research and Training Center's Revised Diabetes Knowledge test 
Performa, 23 items and Morisky medication adherence scale, 4 items, respectively.

Results: Data analysis showed highly significant association among different insulin regimens with respect to the patient education $(p=0.000)$ level. Significant association was found among different insulin regimens and patient's occupational status $(P=0.013)$. However, Statistically non-significant associations were observed among different insulin regimens with gender $(P=0.070)$, marital status $(P=0.183)$ and age $(P=0.084)$ respectively.

Conclusion: In conclusion, data demonstrated that four treatment groups i.e., long acting insulin analogue, ultra-short acting insulin analogue, insulin premix 70/30 analogue insulin pre-mix 50/50 analogue were more effective than two conventional treatment groups i.e., Insulin pre-mix 70/30 and insulin split mix (N \&R) in terms of clinical outcomes in population under study. Furthermore, it was also evident from the data female receiving more insulin than males.

Keywords: Age; diabetes; gender; insulin; marital status.

\section{INTRODUCTION}

Diabetes mellitus is a metabolic disorder due to the defects in insulin secretion and action or both. It is characterized by chronic hyperglycemia with disturbances of fats, carbohydrates and protein metabolism. It has characteristic symptoms such as polyuria, polyphagia, thirst, weight loss and blurring of vision. In its severe cases, ketoacidosis or a nonketotic hyperosmolar state may develop, leading to stupor, coma and, if not treated effectively, death may occur. Persistent hyperglycemia may leads to development of long term complications such as retinopathy, neuropathy, nephropathy, sexual dysfunction in males, hypertension and cardiovascular disease [1]. The diabetes mellitus is classified into two main types: type I diabetes mellitus, characterized by absolute insulin deficiency and type II diabetes mellitus resulted due to altered peripheral insulin resistance and secretion or both. A third form is gestational diabetes mellitus, developed in women during pregnancy. There are some other uncommon types, classified separately as "Other Specific types [2,3].

Diabetes mellitus can be managed by life style modification, oral hypoglycemic agents and insulin [4]. Insulin has different types such as Regular insulin [5], NPH (Isophane insulin), Premixed Formulations, Rapid Acting Analogues [5] and Long Acting Insulin Analogues [6].

The objective of current study was to evaluate the clinical efficacy of different insulin regimens in non-insulin dependent diabetic patients with respect to their age and gender.

\section{MATERIALS AND METHODS}

A prospective cross-sectional study was conducted for comparing different insulin regimens in type II diabetic patients for better glycemic control with respect to age and gender. A total of 234 consenting, known type II diabetic patients, on any insulin regimens, with at least all relevant medical records of preceding three months participated in the study. Patients were segregated into six treatment groups depending upon type of insulin prescribed i.e., insulin premix 70/30, insulin split mix ( $N \& R$ ), long acting insulin analogue, ultra-short acting insulin analogue, insulin pre-mix 70/30 analogue and insulin pre-mix 50/50 analogue, respectively. Moreover, patients from each group were also evaluated regarding diabetes knowledge and medication adherence using Michigan Diabetes Research and Training Center's Revised Diabetes Knowledge test Performa, 23 items and Morisky medication adherence scale, 4 items, respectively.

Patients with confirmed diagnosis of type II diabetes by a registered diabetologist, irrespective of age, gender, social status, comorbidities, diabetic complications, duration of illness and having at least one $\mathrm{HbA} 1 \mathrm{c}$ lab value and lipid profile after insulin usage were enrolled in study. Patients not willing to participate, hospitalized patients, having gestational diabetes, not on any insulin regimen, not having $\mathrm{HbA} 1 \mathrm{c}$ values and lipid profile after insulin usage were excluded from study.

Data was analyzed on SPSS version 22.0 software. One way ANOVA was applied and level of significance was considered 0.05 .

Ethical approval for the study was obtained from Ethical Committee of Clinical Research, University College of Pharmacy, University of the Punjab, Lahore, reference number HEC/PUCP/1927 and Hospital committee of ethics on human research. Informed consent was obtained from all the enrollees. 


\section{RESULTS}

The aim of present study was to evaluate the clinical efficacy of different insulin regimens in non-insulin dependent diabetic patients with respect to their age and gender. Data analysis showed highly significant association among different insulin regimens with respect to the patient education $(P=.000)$ level as shown in Table 1.

Significant association was found among different insulin regimens and patient's occupational status $(P=.013)$ as shown in Fig. 1.

However, statistically non-significant associations were observed among different insulin regimens with gender $(P=.070)$, marital status $(P=.183)$ and age $(P=.084)$ as shown in Figs. 2,3 and Table 2 respectively.

Most of insulin users were females, insulin Pre$\operatorname{mix} 70 / 30(62.5 \%)$, insulin split mix (64.1\%), ultra-short acting insulin analogue (76.2\%) and insulin $70 / 30$ analogue (67.7\%). Though, majority of the patients on long acting insulin (54.3\%) and pre-mix 50/50 insulin analogue (66.7\%) were males. However, little age specific variations were observed among insulin users, insulin premix 70/30 (age range; 40-49 yrs, 39.8\% ), insulin split mix (age range; 40-49, 43.6\%), long acting insulin (age range; 30-39yrs, 45.6\%), ultra-short acting (age range; 40-49 yrs, 42.9\%), insulin $70 / 30$ analogue (age range; 40-49yrs, 38.7\%) and insulin pre-mix 50/50 analogue (age range; $50-59$ yrs, $55.6 \%$ ). Data suggested that most of the enrollees were married, non-smokers and with family history of diabetes. When stratified based on employment status, majority of participants using insulin pre-mix 70/30 were housewives (54.5\%), whereas $43.6 \%$ on insulin split mix, $45.7 \%$ on long acting insulin, $48.4 \%$ on insulin $70 / 30$ analogue, were either selfemployed or salaried. Interestingly, majority of participants on long acting insulin (71.7\%) and insulin $70 / 30$ analogue $(51.6 \%)$ were well educated with more than 10 years of education.

Table 1. Patient's education level with respect to insulin regimens

\begin{tabular}{|c|c|c|c|c|c|c|c|}
\hline \multirow[t]{2}{*}{ Variables } & \multicolumn{6}{|c|}{ Insulin regimens } & \multirow[b]{2}{*}{ P-value } \\
\hline & $\begin{array}{l}\text { Insulin } \\
\text { pre-mix } \\
70 / 30 \\
(n=88)\end{array}$ & $\begin{array}{l}\text { Insulin } \\
\text { split mix } \\
(n=39)\end{array}$ & $\begin{array}{l}\text { Long } \\
\text { acting } \\
\text { insulin } \\
\text { analogue } \\
(\mathrm{n}=46)\end{array}$ & $\begin{array}{l}\text { Ultra } \\
\text { short } \\
\text { acting } \\
\text { insulin } \\
\text { analogue } \\
(n=21)\end{array}$ & $\begin{array}{l}\text { Insulin } \\
\text { pre-mix } \\
70 / 30 \\
\text { analogue } \\
(n=31)\end{array}$ & $\begin{array}{l}\text { Insulin } \\
\text { pre-mix } \\
50 / 50 \\
\text { analogue } \\
(n=9)\end{array}$ & \\
\hline Un-educated & $13(14.8 \%)$ & $7(17.9 \%)$ & $1(2.2 \%)$ & $2(9.5 \%)$ & $1(3.2 \%)$ & $0(0 \%)$ & .000 \\
\hline Educated & $61(69.3 \%)$ & $20(51.3 \%)$ & $12(26.1 \%)$ & $12(57.1 \%)$ & $14(45.2 \%)$ & $5(55.6 \%)$ & \\
\hline $\begin{array}{l}\text { Well } \\
\text { Educated }\end{array}$ & $14(15.9 \%)$ & $12(30.8 \%)$ & $33(71.7 \%)$ & $7(33.3 \%)$ & $16(51.6 \%)$ & $4(44.4 \%)$ & \\
\hline
\end{tabular}

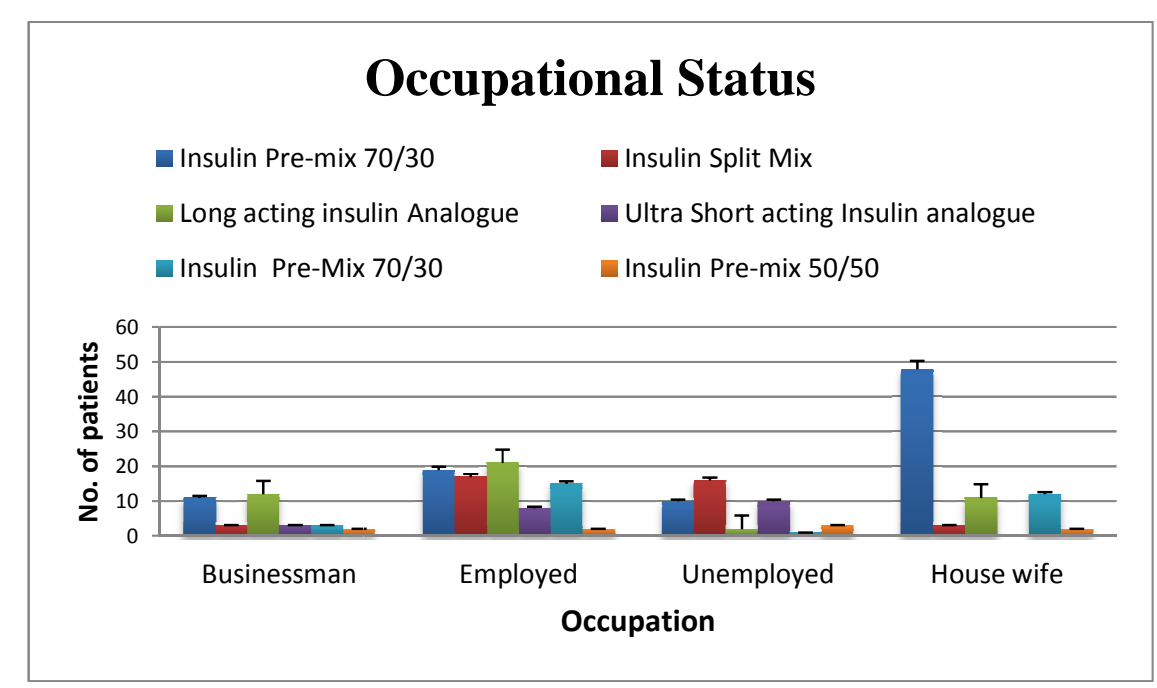

Fig. 1. Occupation based classification of patients on six insulin regimens 


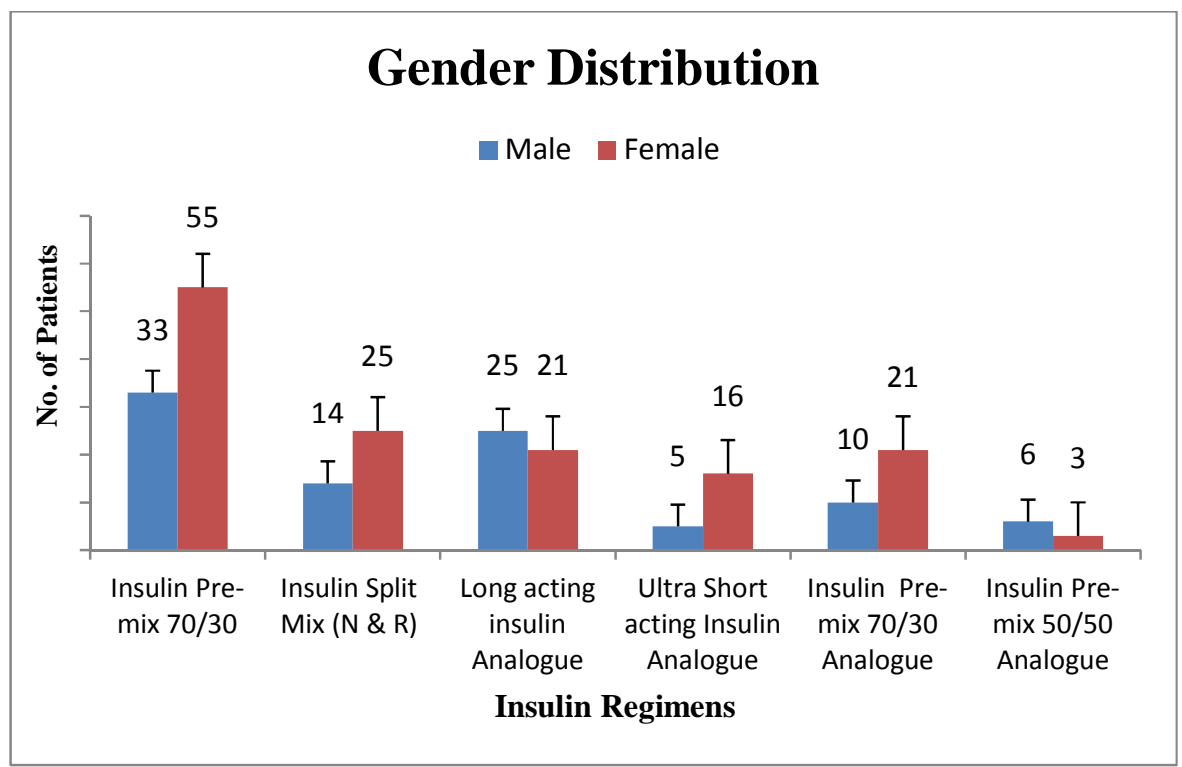

Fig. 2. Gender distribution on the basis of six treatment regimens

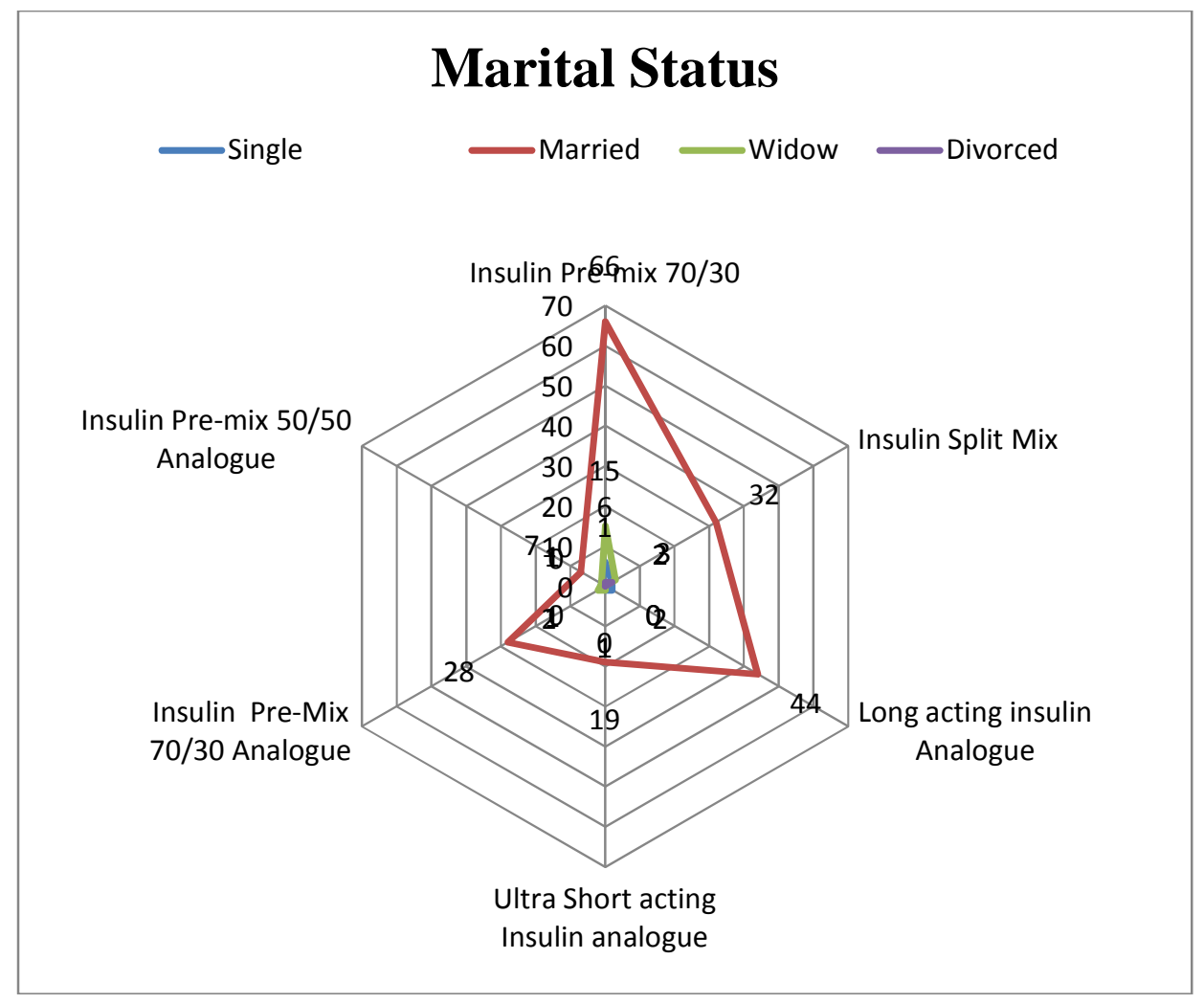

Fig. 3. Marital status based classification of patients on six insulin regimens

The $\mathrm{HbA}_{1} \mathrm{C}$ values with different insulin regimen are shown in Fig. 4. Results are statistically significant among all treatment groups $(P=0.000)$.

\section{DISCUSSION}

Diabetes mellitus has become global metabolic disorder in the world. In the year 2013, it was 
Table 2. Patient's age with insulin regimens

\begin{tabular}{|c|c|c|c|c|c|c|c|}
\hline \multirow{2}{*}{$\begin{array}{l}\text { Age } \\
\text { groups } \\
\text { (Years) }\end{array}$} & \multicolumn{6}{|c|}{ Insulin regimens } & \multirow[b]{2}{*}{$P$-value } \\
\hline & $\begin{array}{l}\text { Insulin } \\
\text { pre-mix } \\
70 / 30 \\
(n=88)\end{array}$ & $\begin{array}{l}\text { Insulin } \\
\text { split mix } \\
(n=39)\end{array}$ & $\begin{array}{l}\text { Long } \\
\text { acting } \\
\text { insulin } \\
\text { Analogue } \\
(n=46)\end{array}$ & $\begin{array}{l}\text { Ultra } \\
\text { short } \\
\text { acting } \\
\text { Insulin } \\
\text { Analogue } \\
(\mathrm{n}=21)\end{array}$ & $\begin{array}{l}\text { Insulin } \\
\text { pre-mix } \\
70 / 30 \\
\text { Analogue } \\
(\mathrm{n}=31)\end{array}$ & $\begin{array}{l}\text { Insulin } \\
\text { pre-mix } \\
50 / 50 \\
\text { Analogue } \\
(n=9)\end{array}$ & \\
\hline $30-$ & & & & $4(19.0 \%)$ & & & .084 \\
\hline $40-49$ & 0 & 17 & 13( & & & $2(2$ & \\
\hline $50-59$ & $29(33.0 \%)$ & $14(35.9 \%)$ & $11(23.9 \%)$ & $7(33.3 \%)$ & $9(29.0 \%)$ & $5(55.6 \%)$ & \\
\hline$>60$ & $17(19.3 \%)$ & $3(7.7 \%)$ & $1(2.2 \%)$ & $1(4.8 \%)$ & $6(19.4 \%)$ & $1(11.1 \%)$ & \\
\hline
\end{tabular}

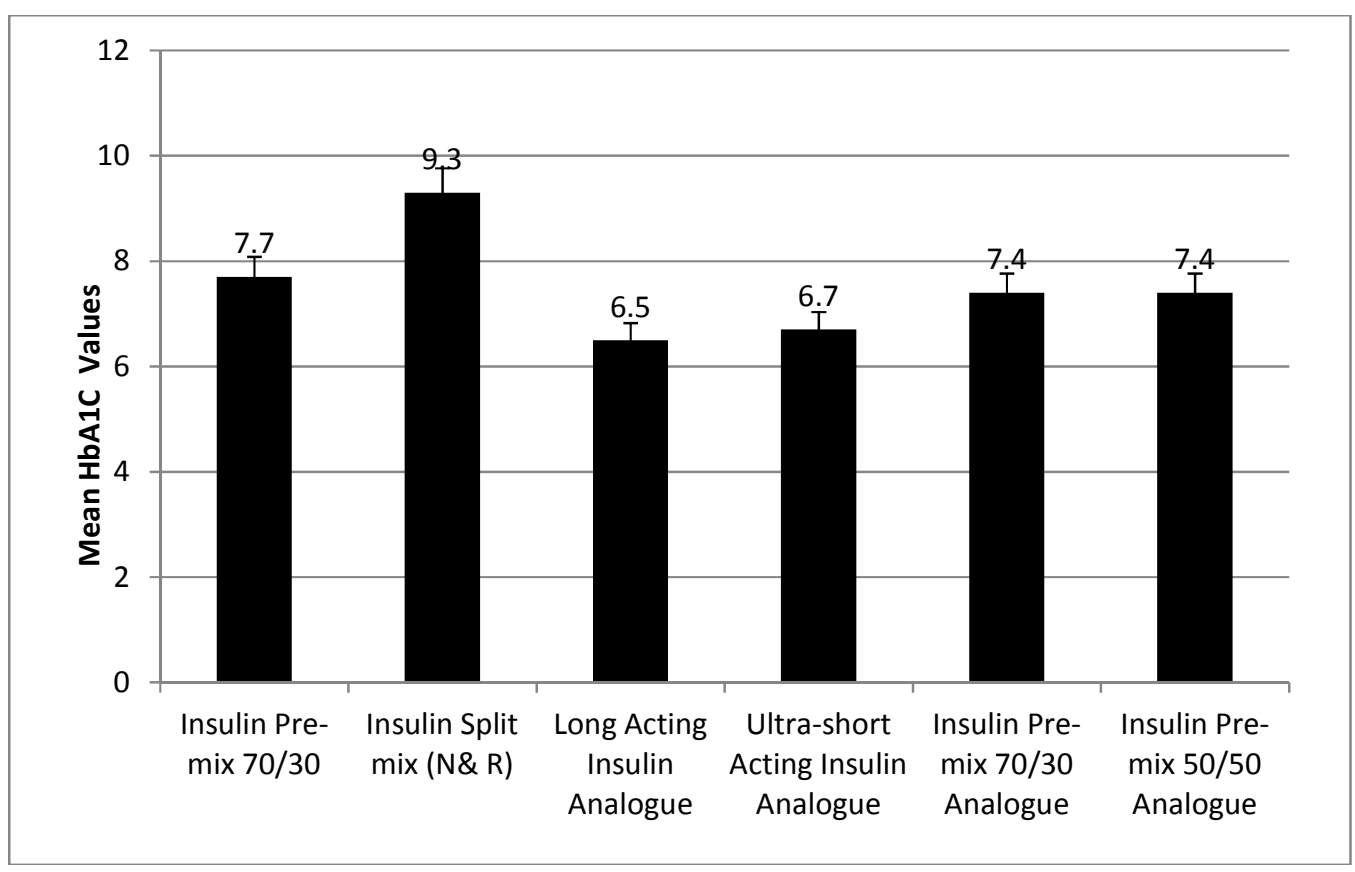

Fig. 4. Treatment regimen wise blood sugar levels

estimated that the worldwide population of diabetes stand 382 million which is expected to reach 592 million by year 2035 [7]. Currently there are 6.9 million patients with diabetes in Pakistan and their number will increase to 11.5 million people by 2025 [8]. In newly diagnosed type II individuals early intensive insulin therapy is effective in glycemic control and recovery/maintenance of beta cell function as compared to oral hypoglycemic agents [9]. As per literature review, some work has been done in past on the prevalence of diabetes, diabetes complications, cost of diabetes in outpatient clinic care and few other topics in Pakistan [10-13]. There is no published data available that demonstrated the comparison of different insulin regimens in diabetic patients in Pakistan.
However, such comparative studies are very common internationally [14-23].

The aim of present study was to evaluate the clinical efficacy of different insulin regimens in non-insulin dependent diabetic patients with respect to their age and gender. Data analysis showed highly significant association among different insulin regimens with respect to the patient education $(P=.000)$ level as shown in Table 1 . Similar findings were observed by Wu et al. [24], whether formal patient education is followed or not. They found that formal patient education did not improve health status. Another study was carried out by Seltzer et al. (1980) on effect of patient education on medication compliance. They found that compliance was 
established to be associated to living alone, fear of side effects, and education about the patient's disorder and treatment. In relation to this, in our study significant association was found among different insulin regimens and patient's occupational status $(P=.013)$ as shown in Fig. 1. However, Statistically non-significant associations were observed among different insulin regimens with gender $(P=.070)$, marital status $(P=.183)$ and age $(P=.084)$ as shown in Figs. 2, 3 and Table 2 respectively. In case of marital status, Acharya et al. [23] performed similar studies [25].

Most of insulin users were females, insulin Premix 70/30 (62.5\%), insulin split mix $(64.1 \%)$, ultra-short acting insulin analogue (76.2\%) and insulin 70/30 analogue (67.7\%). Though, majority of the patients on long acting insulin $(54.3 \%)$ and pre-mix 50/50 insulin analogue (66.7\%) were males. However, little age specific variations were observed among insulin users, insulin premix 70/30 (age range; $40-49 \mathrm{yrs}, 39.8 \%$ ), insulin split mix (age range; 40-49, 43.6\%), long acting insulin (age range; 30-39 yrs, 45.6\%), ultra-short acting (age range; 40-49 yrs, 42.9\%), insulin $70 / 30$ analogue (age range; 40-49 yrs, 38.7\%) and insulin pre-mix 50/50 analogue (age range; $50-59 \mathrm{yrs}, 55.6 \%$ ). Data suggested that most of the enrollees were married, non-smokers and with family history of diabetes. When stratified based on employment status, majority of participants using insulin pre-mix 70/30 were housewives $(54.5 \%)$, whereas $43.6 \%$ on insulin split mix, $45.7 \%$ on long acting insulin, $48.4 \%$ on insulin 70/30 analogue, were either selfemployed or salaried. Interestingly, majority of participants on long acting insulin (71.7\%) and insulin $70 / 30$ analogue (51.6\%) were well educated with more than 10 years of education. Another study was conducted to assess the relationship of diabetes with gender, education, and marital status in an Iranian urban population. They concluded that the prevalence of diabetes mellitus is related to education within the Iranian population. Thus, preventive strategies should be based on the affective factors [24].

\section{CONCLUSION}

In conclusion, data demonstrated that four treatment groups i.e., long acting insulin analogue, ultra-short acting insulin analogue, insulin premix 70/30 analogue insulin pre-mix $50 / 50$ analogue were more effective than two conventional treatment groups i.e., Insulin premix $70 / 30$ and insulin split mix (N \&R) in terms of clinical outcomes in population under study. Furthermore, it was also evident from the data female receiving more insulin than males. Therefore, there is a need to evaluate other factors regarding insulin regimens in future studies.

\section{CONSENT}

As per international standard or university standard, patient's written consent has been collected and preserved by the authors.

\section{ETHICAL APPROVAL}

As per international standard or university standard, written approval of Ethics committee has been collected and preserved by the authors.

\section{COMPETING INTERESTS}

Authors have declared that no competing interests exist.

\section{REFERENCES}

1. Reusch JE. Diabetes, microvascular complications, and cardiovascular complications: What is it about glucose? The Journal of Clinical Investigation. 2003; 112(7):986-88.

2. Mellitus $D$, Diagnosis and classification of diabetes mellitus. Diabetes Care. 2005;28: 37.

3. Association $A D$, Diagnosis and classification of diabetes mellitus. Diabetes Care. 2010;33:62-69.

4. Joshi SR, Parikh RM, Das A. Insulinhistory, biochemistry, physiology and pharmacology. Journal-Association of Physicians of India. 2007;55:19-25.

5. Janka HU, et al. Comparison of basal insulin added to oral agents versus twicedaily premixed insulin as initial insulin therapy for type 2 diabetes. Diabetes Care. 2005;28(2):254-59.

6. Guariguata L, et al. Global estimates of diabetes prevalence for 2013 and projections for 2035. Diabetes Research and Clinical Practice. 2014;103(2):137-49.

7. Qidwai W, Ashfaq T. Imminent epidemic of diabetes mellitus in Pakistan. Issues and Challenges for Health Care Providers. 2010;09:112-13.

8. Weng $\mathrm{J}$, et al. Effect of intensive insulin therapy on $\beta$-cell function and glycaemic 
control in patients with newly diagnosed type 2 diabetes. A multicentre randomised parallel-group trial. The Lancet. 2008; 371:1753-60.

9. Shera A, Jawad F, Maqsood A. Prevalence of diabetes in Pakistan. Diabetes Research and Clinical Practice. 2007;76(2):219-22.

10. Shera AS, et al. Pakistan national diabetes survey. Prevalence of glucose intolerance and associated factors in the Punjab Province of Pakistan. Primary Care Diabetes. 2010;4(2):79-83.

11. Qureshi M, lqbal M, Nomani A. Rapidly increasing prevalence and associations of diabetes mellitus in a rural community of Pakistan. Journal of Diabetology. 2014; 5(3):1-9.

12. Zia A, et al. Prevalence of type 2 diabetesassociated complications in Pakistan. International Journal of Diabetes in Developing Countries. 2016;36(2):179-88.

13. Raskin P, et al. A 16-week comparison of the novel insulin analog insulin glargine (HOE 901) and NPH human insulin used with insulin lispro in patients with type 1 diabetes. Diabetes Care. 2000; 23(11):1666-71.

14. Raskin $P$, et al. Initiating insulin therapy in type 2 diabetes a comparison of biphasic and basal insulin analogs. Diabetes Care. 2005;28(2):260-65.

15. Yki-Järvinen $\mathrm{H}$, et al. Comparison of insulin regimens in patients with non-insulindependent diabetes mellitus. New England Journal of Medicine. 1992;327(20):142633.

16. Boehm B, et al. Premixed insulin aspart 30 vs. premixed human insulin 30/70 twice daily: A randomized trial in type 1 and type 2 diabetic patients. Diabetic Medicine. 2002;19(5):393-99.

17. Bretzel $R G$, et al. Once-daily basal insulin glargine versus thrice-daily prandial insulin lispro in people with type 2 diabetes on oral hypoglycaemic agents (APOLLO): An open randomised controlled trial. The Lancet. 2008;371:1073-84.

18. Hermansen $\mathrm{K}$, et al. Insulin analogues (insulin detemir and insulin aspart) versus traditional human insulins (NPH insulin and regular human insulin) in basal-bolus therapy for patients with type 1 diabetes. Diabetologia. 2004;47(4):622-29.

19. Bennett WL, et al. Comparative effectiveness and safety of medications for type 2 diabetes: An update including new drugs and 2-drug combinations. Annals of Internal Medicine. 2011;154(9):602-13.

20. Siebenhofer $A$, et al. Short acting insulin analogues versus regular human insulin in patients with diabetes mellitus. Cochrane Database Syst Rev. 2006;2:1-71.

21. Singh SR, et al. Efficacy and safety of insulin analogues for the management of diabetes mellitus: A meta-analysis. Canadian Medical Association Journal. 2009;180(4):385-97.

22. Pan $\mathrm{CY}$, et al. Insulin glargine versus NPH insulin therapy in Asian type 2 diabetes patients. Diabetes Research and Clinical Practice. 2007;76(1):111-18.

23. Acharya AS, Singh A, Dhiman B. Assessment of diabetes risk in an adult population using indian diabetes risk score in an urban resettlement colony of Delhi. Journal of the Association of Physicians of India. 2017;65:46.

24. Wu M, et al. Familial history of diabetes is associated with poor glycaemic control in type 2 diabetics. A cross-sectional study. Sci Rep. 2017;7(1):1432.

25. Rahmanian K, Shojaei M, Sotoodeh Jahromi A. Relation of type 2 diabetes mellitus with gender, education, and marital status in an Iranian urban population. Reports of Biochemistry and Molecular Biology. 2013;1(2):64-8.

(C) 2017 Ali et al.; This is an Open Access article distributed under the terms of the Creative Commons Attribution License (http://creativecommons.org/licenses/by/4.0), which permits unrestricted use, distribution, and reproduction in any medium, provided the original work is properly cited.

Peer-review history:

The peer review history for this paper can be accessed here: http://sciencedomain.org/review-history/19311 